\title{
Induced ovulation, mating success and embryonic development in the stripe-faced dunnart, Sminthopsis macroura
}

\author{
D. E. Hickford ${ }^{1}$, N. E. Merry ${ }^{1}$, M. H. Johnson² and L. Selwood ${ }^{1,3 *}$ \\ ${ }^{1}$ Department of Zoology, La Trobe University, Bundoora, VIC 3083, Australia; ${ }^{2}$ Department \\ of Anatomy, Downing Street, University of Cambridge, Cambridge CB2 3DY, UK; and \\ ${ }^{3}$ Department of Zoology, University of Melbourne, VIC 3010, Australia
}

Induced ovulation resulting in normal embryos is rare in marsupials. In this study natural and induced ovulations were compared in mature Sminthopsis macroura $(n=122)$. Comparison of maturation of preovulatory oocytes by ovarian histology and examination of oocytes removed from developing follicles in 12 ovaries of 23 animals receiving 0.058 iu equine serum gonadotrophin (eSG) $\mathrm{g}^{-1}$ with ovaries of 12 animals undergoing natural cycles showed that oocyte maturation was significantly more irregular when it was induced $(P<0.001)$. Postovulatory stages were examined by estimating the number of eggs ovulated from ovarian histology, and by counting oviduct and uterine contents recovered after ovulation. $S$. macroura receiving 0.087 iu eSG ${ }^{-1}(n=34)$, administered as one $(n=17)$ or two $(n=17)$ injections, were significantly $(P<0.05)$ more likely to ovulate $(74 \%)$, mate $(80 \%)$ and have conceptuses $(66 \%)$ than were animals receiving 0.058 iu eSG $\mathrm{g}^{-1}(12,53$ and $0 \%$, respectively) $(n=17)$, and the values were similar to those in animals $(n=36)$ undergoing natural cycles $(100,81$ and $56 \%$, respectively). Induced ovulation using 0.087 iu eSG $\mathrm{g}^{-1}$ yielded significantly $(P<0.05)$ more oocytes per ovary $(20.8 \pm 8.5$; combined data) than did ovulation in animals undergoing natural cycles $(13.7 \pm 3.2)$ (ANOVA, $t$ test). The responses of animals induced in different phases of the oestrous cycle with 0.087 iu $\mathrm{eSG} \mathrm{g}^{-1}$ were not significantly different (ANOVA) with respect to the number of corpora lutea per ovary, conceptuses per animal or days to ovulation after injection. However, the proportion of females that responded after receiving $0.058 \mathrm{iu} \mathrm{eSG}^{-1}$ in the luteal phase was significantly different from that in animals treated with the same dose in the intermediate phase $(P<0.01)$ and in non-cyclic females treated with 0.058 iu eSG $\mathrm{g}^{-1}(P<0.02)$. The main benefits of the treatment were that normal embryos resulted and that $70-78 \%$ of noncyclic animals could be induced to ovulate.

\section{Introduction}

The successful development and refinement of induced ovulation in eutherian mammals, including humans, has contributed greatly to the study of early development and successful fertility treatments (Fowler and Edwards, 1957; Steptoe and Edwards, 1970). It has allowed increased numbers of preovulatory or ovulated eggs to be recovered at times convenient for study or treatment.

Induced ovulation protocols have been applied to marsupials with variable success (for a review see Hinds et al., 1996). Reactions to inducing agents vary among species. In all except one case, the fat-tailed dunnart, Sminthopsis crassicaudata (Rodger et al., 1992), induction of ovulation has not been accompanied by appropriate oestrous behaviour, mating and fertilization.

Current induction protocols fall into two main categories. The first category has been applied successfully to monovular species. Monovular species are spontaneous ovulators, in which behavioural oestrus usually occurs 1-2 days before

*Correspondence

Email: Iselwood@myriad.its.unimelb.edu.au ovulation and in which sperm storage, if it occurs, is transitory. Most work has been done on the tammar wallaby, Macropus eugenii, and the brushtail possum, Trichosurus vulpecula. The most successful protocol that has yielded embryos in these species involves injection of two hormones (Molinia et al., 1998): equine serum gonadotrophin (eSG) followed by pig $\mathrm{LH}$. In both species, ovulation is induced in a high percentage of cases and the number of oocytes is higher than in a natural ovulation. However, mating and fertilization do not occur after the induced ovulation and no conceptuses are found. Milinia et al. (1998) established for both species a protocol for artificial insemination by surgical intrauterine introduction of spermatozoa under anaesthesia, as a result of which oocytes have been fertilized and developed to the four-cell stage. However, no sustained pregnancies have been achieved. It is not known whether this failure to obtain later conceptuses after artificial insemination is because of a deficiency in the oocytes, their surrounding coats or the reproductive tract.

The second type of protocol has been applied to the polyovular species $S$. crassicaudata, in which ovulation is spontaneous, behavioural oestrus occurs up to 5 days before ovulation and spermatozoa can be stored for up to 3 days (Selwood, 1987). This protocol consists of injection 
of eSG only and results in ovulation of a larger number of oocytes than in natural cycles, followed by mating and fertilization to produce conceptuses and, in a small incidence of cases, offspring (Rodger et al., 1992). Results were not improved when eSG injection was followed by administration of $\mathrm{GnRH}$.

The effect of induction of ovulation at different stages of the oestrous cycle or of induction in anoestrous animals has not been determined in either protocol.

Sminthopsis macroura, the stripe-faced dunnart, is a polyoestrous, polyovular, seasonally breeding, carnivorous marsupial that is found in arid and semi-arid regions of northern and central inland Australia. We have a long-term colony of $S$. macroura, in which intensive reproductive monitoring allows the stage of the oestrous cycle to be determined accurately each day. In addition, the time of mating, the day of ovulation (Selwood and Woolley, 1991) and the day of pregnancy can be determined for individual animals to within 0.5 days (Selwood and Hickford, 1999). This model animal and a modification of the induction protocol for $S$. crassicaudata were used for analysis of the ovarian response to eSG and of the conceptuses obtained to determine the optimal time for mating and production of fertilized eggs. This study also investigated whether the response to eSG is affected by the stage of the oestrous cycle and whether animals in anoestrus can be induced to ovulate by hormonal injection.

\section{Materials and Methods}

\section{Animals}

S. macroura were obtained from a long-term colony maintained by L. Selwood since 1985 under permits issued by the Victorian Ministry for Natural Resources and the Environment. Australian National Health and Medical Research Council Guidelines for the care and use of animals for scientific purposes were followed in this study.

\section{Reproductive monitoring}

Females were examined once a day from the beginning of the breeding season in July to the end of the breeding season in February to determine their reproductive status from body weight, pouch condition and microscopic examination of urine samples (Selwood and Woolley, 1991). Urine was collected by pipette on the morning of each day and examined under a microscope to assess the amount of cornified epithelial cells (oestrus) and polymorphonuclear leucocytes (ovulation) on a three-point scale (+: few; ++: common; and +++: highly abundant), and to locate spermatozoa (indicative of mating), yellow crystals and red blood cells (indicative of birth and imminent end of the luteal phase). The oestrous period lasts for about 7 days (equates to the follicular phase, which consists of prooestrus and oestrus) and is characterized by increasing body weight over 5-6 days and increased abundance of epithelial cells $(++$ to +++$)$, followed by a decrease in body weight over 1 or 2 days. Mating usually occurs between day 4 and day 6 of the follicular phase. Ovulation occurs when body weight is lowest and polymorphs appear. This time was deemed day 0 of gestation. The timetable of development (Selwood and Hickford, 1999) was followed to collect conceptuses of known stages during the gestation period of 11 days, which represents the luteal phase (post-oestrus). In cyclic animals this period is followed by an intermediate phase of variable duration (metoestrus) before follicular development recommences.

Some animals were monitored for 60 days if not undergoing oestrous cycles or for at least two oestrous cycles (mean 23.5 days; Woolley, 1990) and other animals were not monitored. Monitored animals were also subjected to ovarian analysis and classified as non-cyclic (no cycle detected, no corpora albicans in ovary) or into stages of the oestrous cycle: follicular, luteal or intermediate, or silently cyclic (no cycle detected from monitoring, but ovary shows corpora albicans). The non-monitored group of animals was subdivided into cyclic and non-cyclic animals on the basis of presence or absence of corpora albicans.

\section{Treatments}

The left ovary was collected from 12 of 23 females

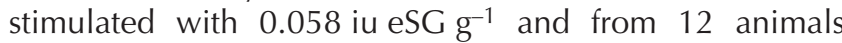
undergoing natural cycles, at days 2-7 (day of ovulation) after injection or of the follicular phase, respectively, to examine the effect of induction on oocyte maturation. The ovaries were maintained in Dulbecco's modified Eagle's medium (DMEM) at $35^{\circ} \mathrm{C}$ and Graafian follicles were punctured using a sterile $30 \mathrm{G}$ mounted needle so that the oocytes could be eased out of the follicle. The oocytes were transferred into fresh DMEM using sterile, pulled siliconized pipettes, counted and sorted into oocyte type on the basis of the features listed (Table 1). Features were based on follicle morphology and on nuclear and cytoplasmic maturation of the oocyte (Merry et al., 1995). The right ovary was examined by ovarian histology (see below).

A control group and three injection treatments were used to examine the effect of induction at different stages of the oestrous cycle on ovarian response, mating and pregnancy. A control group of 36 animals undergoing natural cycles was monitored, paired with a male on days 4, 5 or 6 of the oestrous cycle until mating occurred, and samples were collected and analysed as for the experimental group.

The animals were monitored from the day of injection (day 0) in all three i.p. injection treatments. In the first treatment, 17 animals received a single dose of 0.058 iu $\mathrm{eSG} \mathrm{g}^{-1}$ (Folligon; Allhank Trading Co., South Melbourne), were paired with a male on days 4,5 or 6 after injection until mating was recorded and were killed on days 4, 5, 6, 7 or 8 after injection by halothane. This dose is equivalent to that given to $S$. crassicaudata (Rodger et al., 1992) and represents about 1.3 iu for a $24 \mathrm{~g} S$. macroura. As the ovarian and oocyte analysis for this first treatment showed that ovarian stimulation and oocyte maturation tended to decrease after day 5 and day 6 , did not include excess 
Table 1. Oocytes collected from preovulatory Sminthopsis macroura females

\begin{tabular}{|c|c|c|c|c|c|c|}
\hline $\begin{array}{l}\text { Type of } \\
\text { oocyte }\end{array}$ & $\begin{array}{l}\text { Number of } \\
\text { oocytes } \\
\text { (females) }\end{array}$ & Cumulus cells & $\begin{array}{l}\text { Zona } \\
\text { pellucida }\end{array}$ & $\begin{array}{l}\text { Cytoplasmic } \\
\text { maturation }\end{array}$ & $\begin{array}{l}\text { Nuclear } \\
\text { maturation }\end{array}$ & Type of follicle \\
\hline 1 & $17(3)$ & $\begin{array}{l}\text { Very adherent, } \\
\text { mechanical removal } \\
\text { impossible }\end{array}$ & PVS absent & Absent, vesicles dispersed & GV & Tertiary \\
\hline 2 & $23(4)$ & Adherent, removable & PVS absent & Commenced, vesicles central & GV & Tertiary and antral \\
\hline 3 & $21(5)$ & Absent & PVS present & $\begin{array}{l}\text { Completed, vesicles } \\
\text { concentrated and polarized }\end{array}$ & $\begin{array}{l}\text { Meiotic maturation } \\
\text { to PB1 }\end{array}$ & Antral \\
\hline
\end{tabular}

Oocytes were classified according to follicle type and oocyte cytoplasmic and nuclear maturation.

PVS: perivitelline space; GV: germinal vesicle; PB1: first polar body.

luteinization and led to few animals ovulating, in the second and third treatments the dose was 1.5 times the original or 2.0 iu for a $24 \mathrm{~g}$ S. macroura. For the second treatment, 0.087 iu eSG $\mathrm{g}^{-1}$ was delivered as a single dose and for the third protocol it was delivered as $0.058 \mathrm{iu}$ eSG $\mathrm{g}^{-1}$ on day 0 and 0.029 iu eSG $\mathrm{g}^{-1}$ on day 5. Pairing with males occurred as described above and animals were killed to obtain conceptuses on days 5-24 after injection. Estimates of the day of ovulation were made on the basis of the results of monitoring, which showed that some animals did not ovulate until day 16 after injection.

\section{Ovarian and reproductive tract analysis}

Animals were killed with halothane and the reproductive tract of each was removed, washed and placed in warmed PBS $\left(35^{\circ} \mathrm{C}\right.$, body temperature of the stripe-faced dunnart). The tract was examined and the ovaries were removed. The numbers of antral follicles, corpora lutea and visible corpora albicans were counted for each ovary to confirm the reproductive status of animals and to estimate the number of embryos in the tract from the number of corpora lutea. The transparency of the ovaries meant that follicles and corpora lutea could be counted easily in intact ovaries but it was necessary to confirm the number of corpora albicans by histological examination. The right ovary was fixed in Bouin's fixative for 24-48 h for histological analysis after dehydration, embedding in paraffin wax, cutting into sections (8 $\mu \mathrm{m}$ thickness) and staining in haematoxylin and eosin. For animals undergoing induction with 0.058 iu $\mathrm{eSG} \mathrm{g}^{-1}$, sample sections of ovaries were examined to determine whether luteinization was occurring. Ovaries of animals that ovulated in natural oestrous cycles $(n=18)$ or after induction with 0.087 iu $\mathrm{eSG} \mathrm{g}^{-1}(n=17)$ were cut into serial sections and the total numbers of corpora lutea, corpora albicans, and luteinized and atretic follicles were counted in one ovary from each animal.

\section{Analysis of conceptuses}

The uteri and oviducts were placed in warmed PBS $\left(35^{\circ} \mathrm{C}\right)$. Oviducts were examined using a dissecting microscope set up such that light shone through them, and the number and position of oocytes were noted. Uteri were slit medially and the contents were emptied into PBS for analysis of cleavage stages and into DMEM for analysis of blastocyst stages. The contents were sorted into (i) unfertilized eggs on the basis of the absence of spermatozoa in the mucoid coat and abnormal morphology, (ii) normal conceptuses on the basis of morphology and (iii) failed conceptuses on the basis of evidence of fertilization, abnormal morphology and size (Selwood, 1983; Selwood and Hickford, 1999). When it was difficult to determine the day of ovulation from the monitoring results, it was determined by deducting the day of gestation from the number of days after injection.

\section{Statistical analysis}

The mean and SD were calculated for all measurements, which were analysed by one-way ANOVA followed by Student Newman-Keuls $t$ test where indicated, chi-squared analysis or comparison of proportions using the Shuttle programme (Primer of Biostatistics, Programme Version 4.0, McGraw Hill Inc., 1991). The level of significance was $P<0.05$.

\section{Results}

Oocytes could be classified into three types on the basis of follicle morphology and nuclear and cytoplasmic maturation of the oocyte (Table 1). Tertiary follicles, which were present from the beginning of the follicular phase, had an irregular shape and three to six layers of cells between the oocyte and the follicle edge, and some small spaces between cells. Antral follicles were more rounded and the oocyte occurred two to five cell layers from the follicle edge and contained either a few or one large antral space.

When the high dose of eSG was used, the number of corpora lutea per ovary, conceptuses per animal or days to ovulation after injection did not vary significantly when analysed by ANOVA followed by a $t$ test where appropriate, for any classification of the oestrous cycle (Table 2). Hence, 
Table 2. Induced ovulation using 0.087 iu equine serum gonadotrophin (eSG) $\mathrm{g}^{-1}$ at different stages of the oestrous cycle and in non-cyclic Sminthopsis macroura

\begin{tabular}{|c|c|c|c|c|c|c|c|}
\hline \multirow[b]{2}{*}{ Stage } & \multirow[b]{2}{*}{$n$} & \multirow{2}{*}{$\begin{array}{l}\text { Number of corpora } \\
\text { lutea per ovary } \\
\text { (mean } \pm \text { SD) }\end{array}$} & \multirow{2}{*}{$\begin{array}{c}\text { Number of conceptuses } \\
\text { per animal } \\
(\text { mean } \pm \text { SD })\end{array}$} & \multicolumn{2}{|c|}{$\begin{array}{l}\text { Days to ovulation } \\
\text { after injection }\end{array}$} & \multirow{2}{*}{$\begin{array}{l}\text { Percentage } \\
\text { ovulated }\end{array}$} & \multirow{2}{*}{$\begin{array}{l}\text { Days between } \\
\text { estimated and actual } \\
\text { day of ovulation }\end{array}$} \\
\hline & & & & Range & Mean \pm SD & & \\
\hline Non-cyclic & 10 & $24.8 \pm 7.9(n=7)$ & $11.2 \pm 2.2(n=5)$ & $8-16$ & $11.4 \pm 3.2(n=7)$ & 70 & 2-8 days earlier \\
\hline Follicular & 7 & $16.3 \pm 5.5$ & $8.75 \pm 4.7$ & $3-11$ & $5.3 \pm 3.0$ & 100 & $\begin{array}{l}3 \text { days earlier } \\
1-5 \text { days later }\end{array}$ \\
\hline Luteal & 2 & na & na & na & na & $0^{*}$ & na \\
\hline Intermediate & 6 & $22.8 \pm 11.5(n=4)$ & $14.3 \pm 11.2(n=3)$ & $9-12$ & $10.0 \pm 1.4$ & 100 & 1-7 days later \\
\hline Not monitored & 6 & - & 0 & $2-12$ & $\begin{array}{c}11.0 \pm 8.0 \\
-\end{array}$ & 67 & $\begin{array}{l}1-5 \text { days earlier } \\
5 \text { days later }\end{array}$ \\
\hline Silent & 5 & - & 0 & 14 & - & 20 & 6 days earlier \\
\hline Statistical values & $\begin{array}{l}F \\
P \\
\mathrm{df}\end{array}$ & $\begin{array}{c}1.86 \\
0.193 \\
14\end{array}$ & $\begin{array}{c}0.99 \\
0.399 \\
12\end{array}$ & $\begin{array}{l}- \\
- \\
-\end{array}$ & $\begin{array}{c}2.69 \\
0.071 \\
22\end{array}$ & $\begin{array}{l}- \\
- \\
-\end{array}$ & $\begin{array}{l}- \\
- \\
-\end{array}$ \\
\hline
\end{tabular}

Intermediate: intermediate phase between parturition and evidence of start of follicular phase; not monitored: not monitored but ovary shows evidence of oestrous cycles; silent: no evidence of oestrous cycles from monitoring but ovarian evidence found; na: not applicable.

*One animal had advanced antral follicles.

Table 3. Mean numbers of corpora lutea, luteinized follicles and atretic follicles per ovary, and conceptuses, failed conceptuses and unfertilized eggs per female in Sminthopsis macroura undergoing natural cycles and cycles induced by 0.087 iu eSG g-1 (equine serum gonadotrophin) delivered in one or two injections

\begin{tabular}{|c|c|c|c|c|c|c|c|c|}
\hline \multirow[b]{2}{*}{ Type of cycle } & \multirow[b]{2}{*}{$n$} & \multicolumn{3}{|c|}{ Number per ovary (mean \pm SD) } & \multirow[b]{2}{*}{$n$} & \multicolumn{3}{|c|}{ Number per animal (mean \pm SD) } \\
\hline & & $\begin{array}{l}\text { Corpora } \\
\text { lutea }\end{array}$ & $\begin{array}{l}\text { Luteinized } \\
\text { follicles }\end{array}$ & $\begin{array}{c}\text { Atretic } \\
\text { follicles }\end{array}$ & & Conceptuses & $\begin{array}{c}\text { Failed } \\
\text { conceptuses }\end{array}$ & $\begin{array}{c}\text { Unfertilized } \\
\text { eggs }\end{array}$ \\
\hline Natural & 18 & $13.7 \pm 3.2$ & $2.3 \pm 3.0(n=6)$ & $5.7 \pm 5.6(n=6)$ & 18 & $12.3 \pm 7.1$ & $7.4 \pm 6.3$ & $4.7 \pm 7.6$ \\
\hline Induced (single injection) & 7 & $22.9 \pm 8.2$ & $8.7 \pm 6.9$ & $9.9 \pm 11.6$ & 6 & $11.0 \pm 8.3$ & $15.7 \pm 11.4$ & $10.3 \pm 11.3$ \\
\hline Induced (two injections) & 10 & $19.3 \pm 8.9$ & $10.5 \pm 11.9$ & $9.1 \pm 8.0$ & 8 & $10.0 \pm 4.41$ & $5.3 \pm 6.4$ & $13.3 \pm 16.3$ \\
\hline Induced (total) & 17 & $20.8 \pm 8.5$ & $9.8 \pm 9.9$ & $9.4 \pm 9.3$ & 14 & $10.4 \pm 6.1$ & $9.9 \pm 9.9$ & $12.0 \pm 13.9$ \\
\hline \multirow[t]{3}{*}{ Statistical values } & $F$ & 4.22 & 1.13 & 0.30 & - & 0.36 & 2.38 & 1.48 \\
\hline & $P$ & 0.01 & 0.35 & 0.83 & - & 0.78 & 0.08 & 0.231 \\
\hline & $d f$ & 48 & 36 & 36 & - & 48 & 48 & 48 \\
\hline
\end{tabular}

Induced (single injection): 0.087 iu eSG g-1 $^{-1}$ delivered as a single injection.

Induced (two injections): 0.087 iu $\mathrm{eSG} \mathrm{g}^{-1}$ delivered as two injections.

For the ovarian samples, only animals that had produced corpora lutea were included and for the counts of products of conception only animals that had at least one conceptus were included.

ANOVA statistical values are shown.

results for the effects of induction were pooled subsequently for some analyses when numbers were small. Although the changes in body weight and proportions of cells in the urine samples after injection (data not shown) frequently resembled the changes observed in animals undergoing natural oestrous cycles (Selwood and Woolley, 1991), it was difficult to predict the day of ovulation accurately (Table 2). The proportion of animals that did not ovulate after injection varied with the stage of the oestrous cycle; follicular and intermediate phases were the most responsive. The advantage of the protocol was that $70 \%$ of the non-cyclic animals could be induced to ovulate (Table 2).

When ovarian and embryonic parameters were compared between animals receiving the high dose of eSC (by one or two injections) and those undergoing natural oestrous cycles, the number of corpora lutea per ovary and, hence, the number of oocytes ovulated, varied significantly but no other parameters did (Table 3). The number of corpora lutea per ovary was significantly higher $(P<0.05$; $t$ test) in animals receiving the high dose of eSG as one injection and in the total number of animals receiving the high dose than in animals undergoing natural oestrous cycles. Animals receiving a single injection did not differ significantly from those receiving two injections with respect to all parameters tested (Table 3 ). As a result of this lack of significance between results from animals receiving 
Table 4. Comparison of percentage response of Sminthopsis macroura undergoing natural or induced oestrous cycles with respect to ovulation, mating, number of animals with pouch young or conceptuses of the total number of animals or the number of animals that ovulated

\begin{tabular}{|c|c|c|c|c|c|c|}
\hline Type of cycle & $\begin{array}{l}\text { Number of } \\
\text { animals }\end{array}$ & $\begin{array}{l}\text { Percentage } \\
\text { ovulated }(n)\end{array}$ & $\begin{array}{c}\text { Percentage } \\
\text { ovulated by day } 9 \text { of } \\
\text { follicular phase or } \\
\text { after injection }(n)\end{array}$ & $\begin{array}{c}\text { Percentage } \\
\text { mated between } \\
\text { day } 4 \text { and day } 6 \text { of } \\
\text { follicular phase or } \\
\text { after injection }(n)\end{array}$ & $\begin{array}{l}\text { Percentage with } \\
\text { pouch young or } \\
\text { conceptuses }(n)\end{array}$ & $\begin{array}{c}\text { Percentage of } \\
\text { animals that } \\
\text { ovulated that } \\
\text { had conceptuses }\end{array}$ \\
\hline Natural & 36 & $100(36)$ & $100(36)$ & $81(29)$ & $56(20)$ & na \\
\hline Induced: 0.058 iu eSG $g^{-1}$ & 17 & $12(2)$ & $12(2)$ & $53(9)$ & $0(0)$ & $0(0)$ \\
\hline $\begin{array}{l}\text { Induced: } 0.087 \text { iu } \mathrm{eSG} \mathrm{g}^{-1} \\
\text { (single injection) }\end{array}$ & 17 & $71(12)$ & $47(8)$ & $88(15)$ & $41(7)$ & $58(10)$ \\
\hline $\begin{array}{l}\text { Induced: } 0.087 \text { iu } \mathrm{eSG} \mathrm{g}^{-1} \\
\text { (two injections) }\end{array}$ & 17 & $76(13)$ & $35(6)$ & $71(12)$ & $47(8)$ & $73(12)$ \\
\hline $\begin{array}{l}\text { Induced: } 0.087 \text { iu } \mathrm{eSG} \mathrm{g}^{-1} \\
\text { (total) }\end{array}$ & 34 & $74(25)$ & $41(14)$ & $80(27)$ & $44(15)$ & $66(12)$ \\
\hline
\end{tabular}

eSG: equine serum gonadotrophin; na: not applicable.

the higher dose as either one or two injections, these results were pooled in subsequent comparisons of the effect of the stage of the oestrous cycle on ovulation and effect on days to ovulation after injection.

The low dose ovulation treatment significantly influenced the distribution of types of oocyte recovered on all days before ovulation $(P<0.001)$. For example, in control animals undergoing natural oestrous cycles, day 6 tertiary and antral follicles contained oocytes of either type 2 or 3 , and all oocytes were type 3 in day 7 antral follicles (Fig. 1). In contrast, in 12 animals undergoing cycles induced with 0.058 iu eSG g $^{-1}$, the oocytes in tertiary and antral follicles on days 6 and 7 after injection varied from type 1 oocytes (immature) to type 2 oocytes (showing cytoplasmic maturation) and type 3 oocytes (showing nuclear maturation) (Fig. 1). Of the total number of oocytes collected on each day, the proportion that was collected from animals that received 0.058 iu eSG g ${ }^{-1}$ was significantly higher on days 4,6 and 7 $(P<0.001)$ and day $5(P<0.05)$ than in animals undergoing natural oestrous cycles (Fig. 1). The proportion of luteinized $(8 \%)$ or atretic $(18 \%)$ follicles in animals stimulated with a low dose of eSG was similar to that in animals undergoing natural oestrous cycles (10 and 26\%, respectively).

The percentage of females that ovulated was significantly higher $(P<0.05)$ in females undergoing natural oestrous cycles than in those receiving 0.058 iu eSG g $^{-1}$ or a higher dose, regardless of whether it was administered in one or two injections (Table 4). The percentage of females that had conceptuses or pouch young was about $10 \%$ higher in animals undergoing natural oestrous cycles than in animals in which cycles were induced by the high dose of eSG (Table 4), but with the lower dose (17 animals) no mating occurred and only two of 17 had ovulated to yield either tubal or uterine secondary oocytes on day 7 or day 8 of oestrus. The proportions of animals receiving $0.058 \mathrm{iu}$
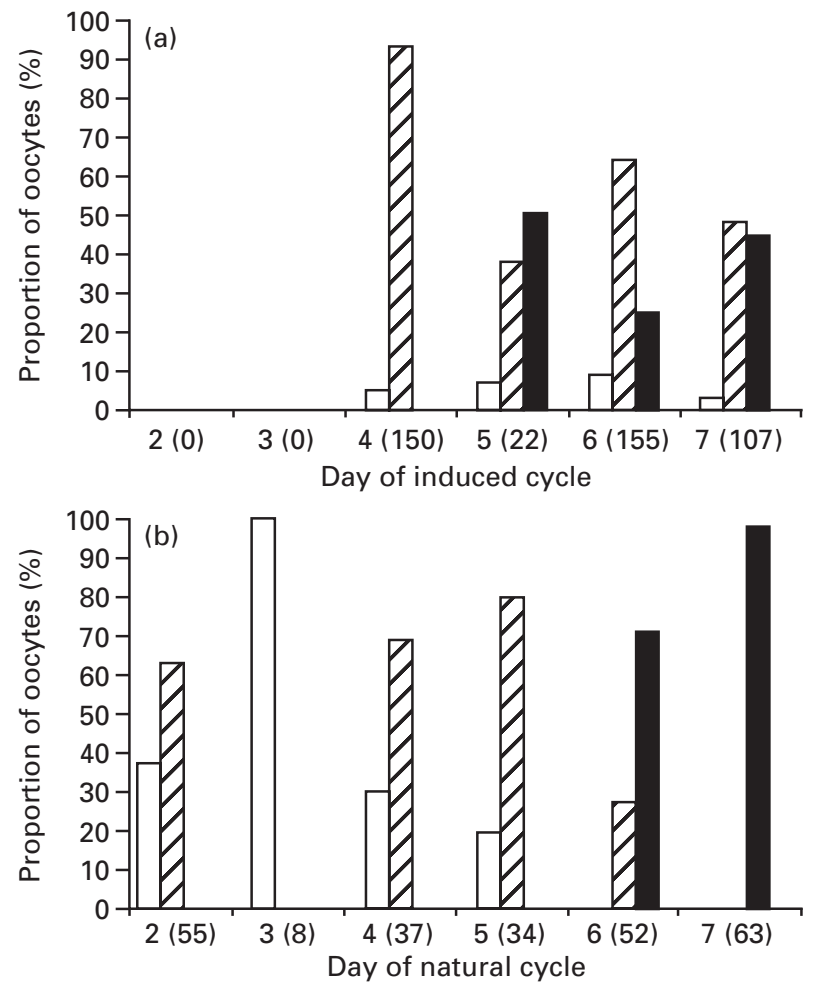

Fig. 1. The proportion of immature ( $\square$ : type 1$)$, maturing ( $\square$ : type 2) and mature ( $\mathbf{\square}$ : type 3) oocytes in (a) female Sminthopsis macroura ( $n=12$ animals, two assessed per day) undergoing induced ( 0.058 iu equine serum gonadotrophin (eSG) $\mathrm{g}^{-1}$ ) oestrous cycles on days 2-7 after injection and in (b) $S$. macroura undergoing natural cycles ( $n=12$, two assessed per day) on days $2-7$ of the follicular phase. The values in parentheses represent the number of oocytes examined on each day. The results are significantly different $(P<0.001)$ on all days except for day 3 $(P<0.05$, chi-squared analysis). 


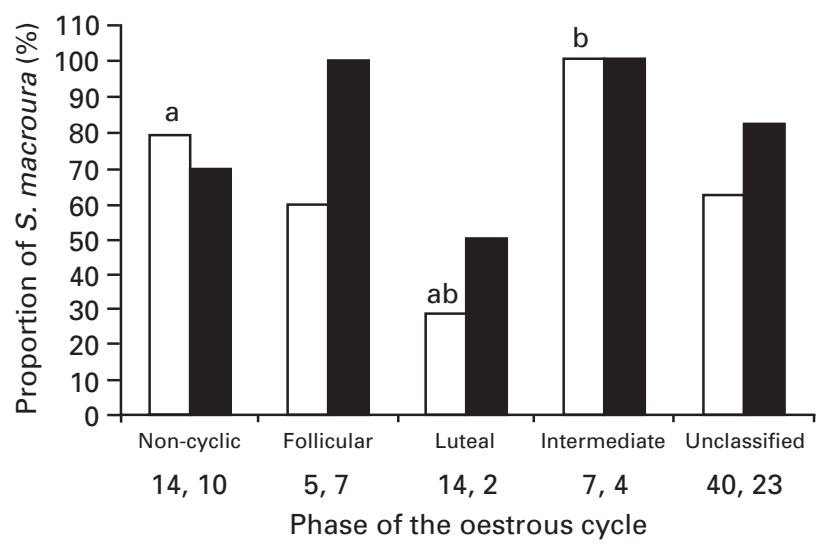

Fig. 2. The proportion of female Sminthopsis macroura that responded to low ( $\square$ : 0.058 iu equine serum gonadotrophin (eSG) $\left.\mathrm{g}^{-1}\right)(n=40)$ and high $\left(\boldsymbol{\square}: 0.087\right.$ iu eSG $\left.\mathrm{g}^{-1}\right)(n=34)$ doses of eSG at different phases of the oestrous cycle. Unclassified: animals that were undergoing silent cycles or were not monitored but were cyclic. The responses of the animals in the two groups were not significantly different at any phase of the oestrous cycle. Values in parentheses are numbers of animals in each group (0.058 and 0.087 iu eSG $\mathrm{g}^{-1}$, respectively). There were significant differences

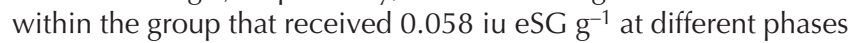
of the oestrous cycle: ${ }^{\mathrm{a}} P<0.01$ and ${ }^{\mathrm{b}} P \leqslant 0.02$.

$\mathrm{eSG} \mathrm{g}^{-1}$ that ovulated, mated or were pregnant were significantly $(P<0.05)$ lower than those in animals that received 0.087 iu eSG $\mathrm{g}^{-1}$ in one or two injections. There was no significant difference in the proportion of animals responding between those that received one or two injections (Table 4). Most animals undergoing natural cycles ovulate on day 7 after the onset of the oestrous period. Some animals that received the higher dose in a single injection were more passive on the day after the injection, indicating that the single injection may have caused nausea. In natural oestrous cycles, of 37 matings that resulted in pouch young or conceptuses, $24 \%$ occurred on day $4,41 \%$ on day 5 and $31 \%$ on day 6 of the follicular phase. In cycles induced using the high dose of eSG, of eight matings where the day was recorded, $25 \%$ occurred on day $4,25 \%$ on day 5 and $50 \%$ on day 6 after injection.

The effects of injection with 0.087 iu eSG g $^{-1}(n=34$ animals) and 0.058 iu eSG g $^{-1} \quad(n=40$ animals $)$ were compared for antral follicle development and ovulation and showed that the ovulatory outcome was not significantly different between treatments (Fig. 2). However, when comparisons were made within each treatment, the proportion of animals that responded after receiving 0.058 iu eSG g $^{-1}$ in the luteal phase was significantly lower than that in animals treated with the same dose in the intermediate phase $(P<0.01)$ and in non-cyclic females treated with 0.058 iu eSG g $^{-1}(P<0.02)$. Eleven animals that received the high dose of eSG were not included in these results because no monitoring results were available to assign them to stages of the oestrous cycle, but ten of these animals responded to treatment.

\section{Discussion}

Induction of ovulation at different stages of the oestrous cycle has not been examined previously in marsupials. In the present study, except for non-cyclic animals, the proportions of animals in different reproductive states responding to

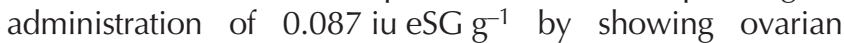
stimulation (preovulatory) or corpora lutea or conceptuses (postovulatory) were usually higher than the proportions responding after administration of $0.058 \mathrm{iu} \mathrm{eSG} \mathrm{g}^{-1}$. There were no significant differences between groups with respect to the number of eggs ovulated (corpora lutea per ovary) or the number of conceptuses per animal. It is possible that if greater numbers were examined significant differences might emerge. However, when comparisons were made within each treatment group, the rate of ovulation was significantly lower in animals that received the lower dose of eSG $\left(0.058\right.$ iu g $\left.^{-1}\right)$ in the luteal phase compared with those treated in the intermediate phase and treated non-cyclic animals. It is possible that in cyclic animals the high progesterone concentrations in the mid-luteal phase (Selwood and Woolley, 1991) suppress an ovulatory response. Although the differences were not significant, the combination of the relatively fewer days to ovulation, number of corpora lutea per ovary and conceptuses per animal, and their similarity to what happens in natural cycles (Selwood and Woolley, 1991) indicates that the follicular phase may have been affected least by injection of 0.087 iu eCG $\mathrm{g}^{-1}$. A considerable benefit of the protocols is that non-cyclic animals and animals undergoing silent cycles can be induced to ovulate, mate and produce conceptuses. This is advantageous in the management of rare marsupial colonies.

There has been no comparable analysis of follicle and oocyte maturation during natural and induced cycles in polyovular marsupials. In the present study it has been shown that in the follicular phase in natural oestrous cycles, the initiation of oocyte maturation as shown in type 2 oocytes occurs during the transition from tertiary to Graafian follicles and begins as early as day 2. Numbers increase after day 4 and mature type 3 oocytes showing both nuclear and cytoplasmic evidence of maturation are confined to days 6 and 7 (day of ovulation). The maturational changes described here are associated with major changes in cytoskeletal architecture associated with increasing polarization of the yolk vesicles in the pole opposite the nuclear material (Merry et al., 1995). In animals stimulated by 0.058 iu eSG $\mathrm{g}^{-1}$, type 2 oocytes appear on day 4 , but the transition to type 3 oocytes appears earlier and less consistently than in natural cycles. It seems likely that the failure to make this transition effectively may account for the low proportion of animals ovulating after administration of the lower dose of eSG.

As in other cases of induced ovulation in marsupials (Rodger et al., 1992; Hinds et al., 1996; Molinia et al., 1998), 
when oocytes were ovulated, the number was significantly increased. With 0.087 iu eSG g ${ }^{-1}$, the number of viable conceptuses was similar to that in natural cycles, indicating that if the animals had been allowed to give birth the normal number of pouch young would be expected unless the injection protocol caused fetal mortality in the last 1-2 days of pregnancy. In the only other study of a polyovular marsupial, Sminthopsis crassicaudata (Rodger et al., 1992) in which induced ovulation led to viable conceptuses, the number of viable conceptuses or pouch young was not given, so it is not possible to make comparisons.

An interesting feature of induced ovulation using 0.087 iu eSG $\mathrm{g}^{-1}$ was that sperm survival in the oviduct appeared to be enhanced. In natural cycles in S. macroura, matings that occur $>5$ days before ovulation do not result in viable conceptuses and failure of cleavage is common (L. Selwood, unpublished). In contrast, using the induction protocols for 0.087 iu eSG $g^{-1}$ in the present study, sperm fertilizing capacity was maintained for 10 days, which is indicative of an enhancement of the oviductal environment.

Although the number of follicles stimulated was similar in animals that received either 0.058 or 0.087 iu eSG $\mathrm{g}^{-1}$, the proportion of animals that ovulated by day 9 after injection and the proportion that mated were higher in animals that received 0.087 iu eSG $\mathrm{g}^{-1}$ and resembled more closely the proportions found in natural oestrous cycles. In $S$. macroura that received 0.058 iu $\mathrm{eSG}^{-1}$, the proportion that mated (53\%) was similar to the proportion of $S$. crassicaudata that mated (55\%) after treatment with eSG at similar concentrations (Rodger et al., 1992). In S. macroura treated with 0.087 iu $\mathrm{eSG} \mathrm{g}^{-1}$, the proportion of animals that mated was higher (total $80 \%$ ) but the proportion with conceptuses or pouch young (total 44\%) was lower than in the $S$. crassicaudata (50\%) study, except in the S. macroura that received the eSG as two injections, which resulted in a similar proportion of animals (47\%) with conceptuses. The general conclusion for $S$. macroura is that administration of 0.087 iu eSG $\mathrm{g}^{-1}$ as two injections, with matings on days 4-6 after injection, produced the most favourable results for obtaining conceptuses.

The major disadvantage of the induced ovulation protocol using the high dose (two injections) was that the timing of ovulation was unpredictable. One possible solution would be to perform the induced ovulation on juvenile females, which works well in mice (Runner and Palm, 1953), but in practice would be of little advantage because no males would be in season. Other hormones could be used after administration of eSG to make the timing of ovulation more precise, but hormones used in other dasyurids have not proven successful. In $S$. crassicaudata, GnRH does not improve the outcome (Rodger et al., 1992), whereas administration of hCG induced ovulation and mating occurred, but no offspring resulted (Smith and Godfrey, 1972). Administration of relatively high concentrations of eSG followed by hCG in Dasuroides burnei induced oestrus but few matings occurred (Hinds et al., 1996). Nevertheless, delivery of a second hormone to provide the $\mathrm{LH}$ stimulus is a possible solution to make the timing of ovulation more precise.

In conclusion, the results of the present study indicate that administration of 0.087 iu eSG g ${ }^{-1}$ in $S$. macroura is likely to induce an oestrous cycle and increases the likelihood of mating and conception. It is possible that the quality of oocytes produced after administration of 0.058 iu eSG $\mathrm{g}^{-1}$ is inferior and, hence, they are less likely to ovulate. The number of oocytes ovulated per female using the higher dose of eSG was significantly higher than that in animals undergoing natural cycles, but the number of conceptuses per animal was not significantly higher. Non-cyclic animals could be induced to ovulate, mate and conceive using these induction protocols.

This research was funded by the Australian Research Council. The authors would like to thank T. S. Selwood for advice on statistical analysis and L. Masini, who assisted with animal monitoring.

\section{References}

Fowler RE and Edwards RG (1957) Induction of superovulation and pregnancy in mature mice by gonadotrophins Journal of Endocrinology 15 374-384

Hinds LA, Fletcher TP and Rodger JC (1996) Hormones of oestrus and ovulation and their manipulation in marsupials Reproduction, Fertility and Development 8 661-672

Merry NE, Johnson MH, Gehring CA and Selwood L (1995) Cytoskeletal organization in the oocyte, zygote, and early cleaving embryo of the stripe-faced dunnart (Sminthopsis macroura). Molecular Reproduction and Development 41 212-224

Molinia FC, Gibson RJ, Brown AM, Glazier AM and Rodger JC (1998) Successful fertilization after superovulation and laparascopic intrauterine insemination of the brushtail possum, Trichosurus vulpecula, and tammar wallaby, Macropus eugenii. Journal of Reproduction and Fertility 113 9-17

Rodger JC, Breed WG and Bennett JH (1992) Gonadotrophin induced oestrus and ovulation in the polyovulatory marsupial Sminthopsis crassicaudata. Reproduction, Fertility and Development 4 145-152

Runner MN and Palm J (1953) Transplantation and survival of unfertilized ova of the mouse in relation to postovulatory age Journal of Experimental Zoology 124 303-316

Selwood L (1983) Factors influencing pre-natal fertility in the brown marsupial mouse Antechinus stuartii. Journal of Reproduction and Fertility $68317-324$

Selwood L and Hickford D (1999) Early cell lineages in marsupial embryos. In Cell Lineage and Fate Determination pp 505-519 Ed. SA Moody. Academic Press, San Diego

Selwood L and Woolley P (1991) A timetable of embryonic development and ovarian and uterine changes during pregnancy, in the stripe-faced dunnart, Sminthopsis macroura (Marsupialia: Dasyuridae) Journal of Reproduction and Fertility $91213-227$

Smith MJ and Godfrey GK (1970) Ovulation induced by gonadotrophin in the marsupial, Sminthopsis crassicaudata (Gould) Journal of Reproduction and Fertility 22 41-47

Steptoe PC and Edwards RG (1970) Laparoscopic recovery of preovulatory human oocytes after priming of ovaries with gonadotrophins Lancet 1 683-689

Woolley PA (1990) Reproduction in Sminthopsis macroura (Marsupialia: Dasyuridae). 1. The female Australian Journal of Zoology 38 187-205

Received 1 December 2000.

First decision 19 February 2001.

Revised manuscript received 8 June 2001.

Accepted 4 July 2001. 